\title{
AN INVESTIGATION OF THE DESIGN IMPLICATIONS FOR OPENINGS IN A SUB-STANDARD MEDIAN ON A MULTI-LANE DIVIDED HIGHWAY
}

\author{
Suchitra C ${ }^{1}$, B.V. Kiran Kumar ${ }^{2}$, Jim Jarvis ${ }^{3}$ \\ ${ }^{1}$ Project Engineer, ${ }^{3}$ Team Leader, Road Safety Management Project, VicRoads, K.R. Circle, Bangalore-560001 \\ ${ }^{2}$ Associate Professor, Department of Civil Engineering, Govt. SKSJTI, K.R. Circle, Bangalore-560001
}

\begin{abstract}
The main objective of this study was to provide background information for engineers to make decisions on closure, spacing and design of median openings on multilane divided highways with substandard medians and to identify the key issues associated with such decisions. The information made available should contribute to the development of a strategy for closing medians to arrive at the best compromise between safety and mobility. State Highway-17 in the state of Karnataka, was selected as a pilot corridor for this study which has a major safety concern of informal median openings. Based on the analysis of the crash data, a section of $5 \mathrm{~km}$ was selected to carry out detailed traffic studies at all the median openings. It was found that the turning movements along the corridor are dominated by motorized two wheelers. It was then concluded that the median openings along the highway should be tailored to the dominating vehicle type. The study suggests that the informal median openings are due to longer diversion caused by the closure of openings. It was also found that many informal median openings shown to be related to motor related trade and other outlets. This needs to be considered in the strategy.
\end{abstract}

Keywords: Substandard medians, key issues, strategy, safety and mobility, dominating vehicle type, turning movements, motor related trade.

\section{INTRODUCTION}

With the rapid increase of vehicles on Indian highways; casualties due to crashes are increasing year after year. In India during 2012 the number of crashes was as high as 600000 with 147000 fatalities, resulting in an economic loss of around 3 to $4 \%$ of GDP. The injuries and deaths due to crashes are a global phenomena but more severe on Indian multilane highways with prevailing mixed traffic conditions. Now, road safety has become a growing concern for both highway professionals as well as the public, as crashes are a major source of loss of life. Furthermore, there is great economic loss caused by property damage or loss of working days resulting from injuries and fatalities, estimated at billions of rupees annually. Concepts of sustainable safety and quality management have gained importance in past decades that has led policy makers and project managers to realize the need for specifically safety-oriented tools. Highways and streets have dual roles which are competing, namely providing property access as well as moving of through traffic. Highway classification system have identified the competition between access and flow, which generally specifies that principal arterial streets primarily move traffic and secondarily provide access while local streets primarily provide access and secondarily move traffic. If attempting to simultaneously provide both mobility and access on the same street, and improper planning and inadequate control of access, it can quickly lead to increased number of crashes along roadways. This relationship is illustrated in Figure 1. The movements that occur on and off the roadways at driveway locations, when they are too closely spaced, cause difficulties for through traffic to flow smoothly at desired speeds and levels of safety. Unfortunately many Indian roads are forced to provide both mobility and access functions resulting in conflicting use of the carriageway. 


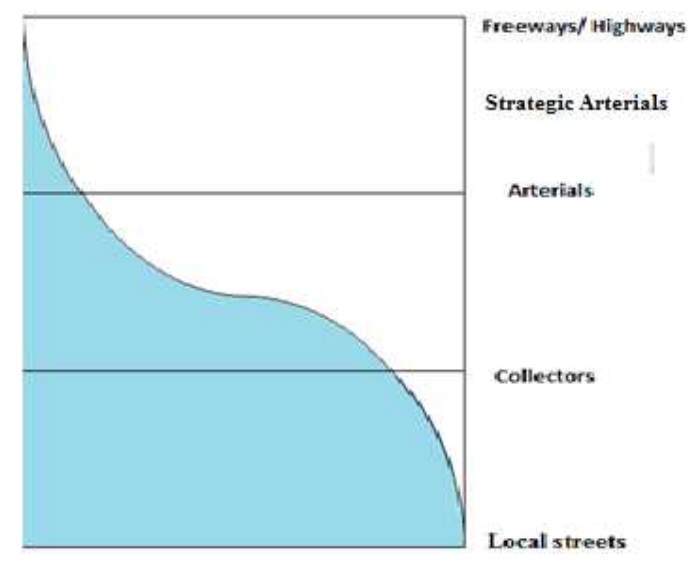

(Source: ITE Committee 6Y-19, Planning Urban Arterial and Freeway Systems,Institute of Transportation Engineers, Washington, D.C., 1988.)

Fig1. Competing Mobility and Access functions

This study concerns multi-lane highways divided by a median. Medians are the structures used to separate opposing lanes of traffic and enhance the safety of motorists on multilane highways. Most of the State and Local road agencies are considering installing medians that are non-traversable on multilane highways to improve safety and travel times. Business and property owners often resist such improvements since this may deny them and their customers the opportunity of direct right-turn access to or from their property. Traffic destined for such locations must use alternate routes; some may involve making U-turns at the nearest median openings. The nature of medians plays a crucial role in the safety of divided highways and will be examined in this study.

\section{MEDIAN OPENINGS}

Medians which were built in India before the year 2000 were often narrow and did not have sufficient space to provide protective turn lanes at median openings for turning vehicles. The IRC "Guidelines for Control of Access on Highways", published in 2000[1] states that the minimum desirable median width should be $5 \mathrm{~m}$ and can be reduced to $3 \mathrm{~m}$ if land is restricted. Even with $3 \mathrm{~m}$ wide median, protective turning lanes can be provided, but it seems that many Indian multilane divided highways have been built with substandard medians which are proving to be inadequate for providing turning lanes leaving turning vehicles at risk of being struck or causes a hazard for other vehicles

While the information on median openings is relatively sparse, some is available:

- $\quad$ The minimum spacing of openings in a median on rural highways in India is $2 \mathrm{~km}$, wherein additional controlled openings can be made during repair and rehabilitation works, IRC:SP:84-2009 [2].
- In the United Sates, intersections of streets should only be provided with median openings with spacing between median openings which is adequate for introduction of turn lanes. Traffic volumes, urban-rural area characteristics, and type of turning vehicles form the basis for the design of median openings and median ends AASHTO Green Book [3].

- The work of Cribbins [4] showed that under the conditions of low traffic volumes, wide medians, and light road side development, median openings are not necessarily crash prone. However frequent median openings do have significant effect on crashes as volume increase and road side development increases.

- In Florida overall reductions in the number of median openings resulted in crash rate reduction and also by reducing number of conflict points traffic flow characteristics can be improved at remaining openings [5].

- $\quad$ Stover [6] suggests that median access control results substantial reduction of crashes and associated social and economic costs, achievable by installing non traversable median with specifically designed openings.

- It is often believed by business representatives that customers give less importance to property access than either quality or service, NCHRP Report 395 [7]. However, some businesses, like auto related trades, may have to provide good and reliable services if a reduction in access are to be overcome.

Some of the key issues raised by the information found on medians are: the decision to provide median opening should be based on the traffic volumes, rural-urban characteristics and turning vehicle composition. While it if often believed by business owners that customers give less importance to property access than either quality or reliable services. But auto related trades like fuel stations, tend to place a high premium on access.

\section{RESEARCH OBJECTIVE}

The main aim of this research is to provide background information and support for engineers to make strategic decision on closure, spacing and design of median openings on multilane divided highways with substandard medians and to identify the key issues to arrive at such decisions. The information made available should contribute to the development of a strategy for closing medians to arrive at the best compromise between safety and mobility.

\section{DESCRIPTION OF STUDY SITE}

State Highway-17 in the state of Karnataka was selected as a pilot corridor for the present study, it is a four lane divided road with a raised curb median (1.8 $\mathrm{m}$ wide) with a few stretches of paved shoulder. The highway runs for approximately $140 \mathrm{~km}$ connecting Bangalore to Mysore which 
is a heritage city attracting good number of tourists. There are no service roads in urban areas, and while there are occasional truck lay-bys and other road facilities provided in both directions, there are few provisions for buses to pick up and drop off passengers safely. The study section selected is of approximately $53.8 \mathrm{~km}$ from Maddur, at Malavalli junction, to the Ring Road-Bangalore-Mysore Road junction on the fringe of Mysore. There are 3 towns along the route (Maddur, Mandya and Srirangapattana) and many villages on either side of the road or divided by SH-17

\section{METHODOLOGY}

- Approximately $53.8 \mathrm{~km}$ out of $140 \mathrm{~km}$ of the highway was selected for the study.

- Before carrying out the actual traffic data collection, the crash data, which was from all the local police stations along the highway, was collected for the available number of years to study the vehicle composition of crashes.

- Based on the analysis of crash data, a section of $5 \mathrm{~km}$ was selected to carryout detailed traffic study. The short study section is from chainage $\mathrm{km} \mathrm{103.8(Induvalu)} \mathrm{to} \mathrm{km}$ 108.8(Tubinakere industrial area).

- Traffic studies were carried out to collect the information on through traffic volume, and volume and composition of turning vehicles at all eight median openings along the short section.

- Analysis of the collected data was carried out to arrive at results and conclusions.

\section{DATA COLLECTION}

The set of data collected is as follows:

1. Crash data: Crash data was collected from five different local police stations along $53.8 \mathrm{~km}$ of the highway for the available period (2008-2011).

2. Classified Traffic Volume Counts: A traffic volume survey was carried out in one of the median opening locations to understand the nature and characteristics of through traffic on highway.

3. Classified Turning Movement Counts: Turning movement surveys were carried out at all median opening locations. Counts have been carried out manually by enumerators for a total eight hour period in two sessions i.e. from morning 8.00 am to $12.00 \mathrm{pm}$ as first session and from afternoon $2.00 \mathrm{pm}$ to evening $6.00 \mathrm{pm}$ as second session.

4. Pedestrian Counts: It was evident from the crash reports that the most vulnerable road users are the Pedestrians. Therefore it was necessary to count pedestrians crossing the highway, which is useful for identifying better pedestrian crossing facilities.

5. Median Openings: A count of all the median openings along $53.8 \mathrm{~km}$ section of the highway was collected to get the number of median openings in the study section.

\section{DATA ANALYSIS}

Analysis of the data indicated that for the research section:

- Both deaths and injuries are stable- perhaps even reduced during this period except for a significant increase in fatalities in 2011 as shown in Table 1.

Table 1: Crash data Summary

\begin{tabular}{c|c|c|c}
\hline Year & $\begin{array}{c}\text { Total } \\
\text { No. of } \\
\text { crashes }\end{array}$ & $\begin{array}{c}\text { Total } \\
\text { No. of } \\
\text { deaths }\end{array}$ & $\begin{array}{c}\text { Total } \\
\text { No. of } \\
\text { injured }\end{array}$ \\
\hline 2008 & 873 & 149 & 999 \\
\hline 2009 & 774 & 101 & 688 \\
2010 & 781 & 100 & 819 \\
\hline 2011 & 680 & 174 & 783 \\
\hline Total & 3108 & 524 & 3289 \\
\hline
\end{tabular}

- Pedestrians are the highest road user type affected constituting to around $30 \%$ followed by the motorized two wheelers with $28 \%$ and cars with $21 \%$.

- The data analyzed on the traffic volume count reveals that the car/jeep/van forms the major through traffic on SH-17 occupying almost $53 \%$ of the total vehicle composition. Motorized two wheelers occupy second place with $27 \%$ of the total vehicles. And the remaining percentage is taken over by other class of vehicles.

- Motorized two wheelers constitute the highest volume of traffic making U-turns on $\mathrm{SH}-17$ with as high as $72 \%$ of the total vehicles, followed by cars with $10 \%$ and then by Light Commercial Vehicles with $9 \%$. Number of trucks making u-turn is almost negligible when compared to motorized two wheelers volume as shown in Figure 2.

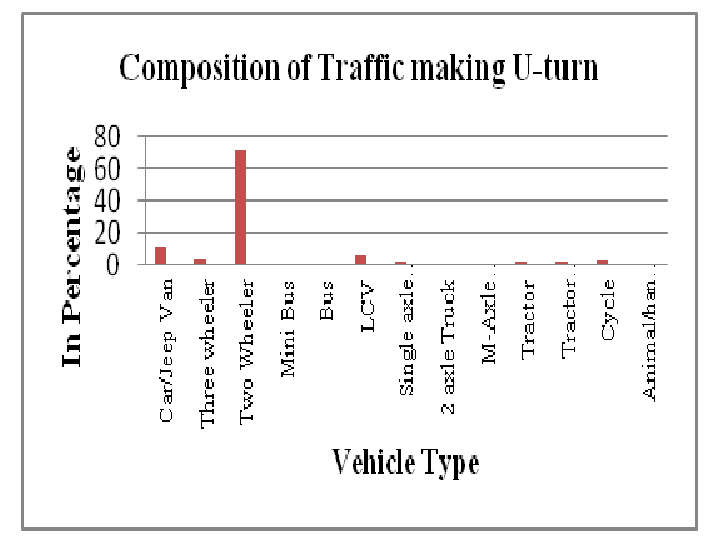

Fig2: U-turn traffic composition 
- As with U-turning traffic, right turns are also dominated by Motorized two wheelers with almost $69 \%$ followed by cyclists with $8 \%$ and then by cars with $5 \%$ as shown in Figure 3.

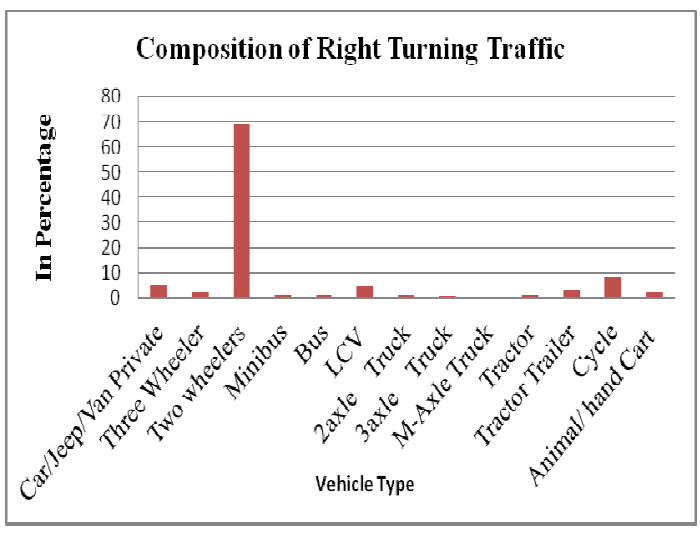

Fig 3: Right turn traffic composition

- The tuning traffic making both U-turns and right turns are composed of mainly motorized two wheelers. This could mean such vehicles are making short trips from one village to the other along the highway and even trips between agricultural fields to villages and market outlets.

- The turning movement data collected in the data collection stage has been analyzed and an attempt was made to find out the relationship between distance of cross road generating the amount of traffic from the nearest median opening and the number of U-turners. The relationship shows a scattergram as shown in Figure 4.

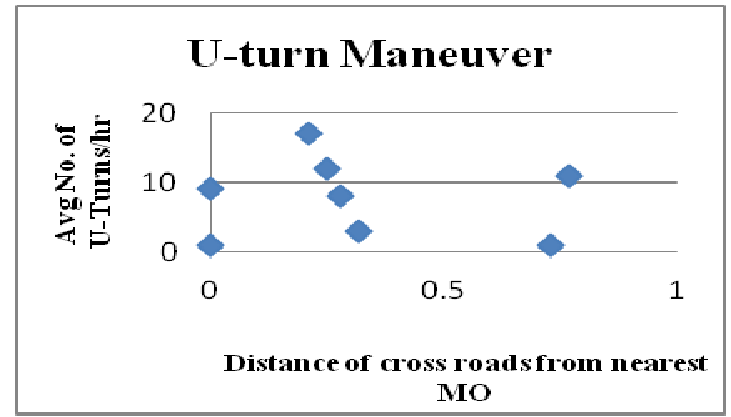

Fig4: U-turn Maneuvers

Table 2: Median openings along selected section of SH-17

\begin{tabular}{|c|c|}
\hline $\begin{array}{c}\text { No. of } \\
\text { Formal } \\
\text { Median } \\
\text { Openings }\end{array}$ & $\begin{array}{c}\text { No. of } \\
\text { Informal } \\
\text { Median } \\
\text { Openings }\end{array}$ \\
\hline 79 & 16 \\
\hline
\end{tabular}

As seen from Table 2 , it is clear that along $53.8 \mathrm{~km}$ of selected section of $\mathrm{SH}-17$, the total median openings are 95 in which 79 openings are the formal median openings and remaining 16 such openings are informal. It was noticed from field observations that informal median openings were often may serving fuel station be due to the following reasons:

$>$ Direct U/right turn access

$>$ Access to the road side activities

$>$ Access to Auto-related business such as service stations, etc. A photograph of one such informal median opening serving fuel station is shown in Figure 5

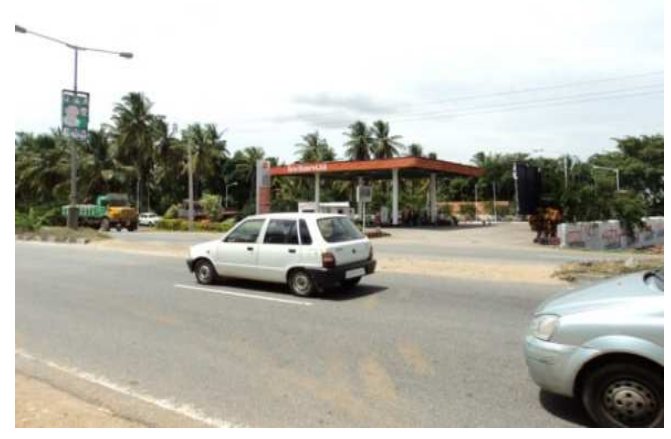

Fig5: Informal Median Opening

\section{RESULTS AND CONCLUSIONS}

- Location: Most of the police reported crashes occurred at median openings. This reconfirms the need to concentrate on median openings.

- Road User Type: Cars form the highest road user type on SH-17. Considerable numbers of pedestrian cross the highway particularly near sections where there are settlements on both sides of the highway.

- Percentage of vehicles and Road Users Involved: As car forms the major through traffic on the highway, police reported crash data also shows that highest percentage of cars are involved in crashes. While considering injured and fatalities, pedestrians are the most affected road user type, which suggests that large number of pedestrians are hit by cars. Pedestrians, together with cyclists and motorized two wheelers, constitute to about $60 \%$ of total causalities, which therefore require major protection from road design.

- Turning Manoeuvres: The turning movements are dominated by motorized two wheelers. This indicates the nature of the turning traffic, which appears to be plying short trips mainly between villages along the highway, from villages to agricultural fields and to the market outlets. It is important to realize that, it may not be possible to make provision in design of median opening for all class of vehicles, which can be decided based upon the composition of turning traffic. In the study corridor this is motorized two wheeler traffic, design of median 
openings should be tailored for such a class of vehicles making turning manoeuvres.

- Median Openings: There seem to be no relationship exists between distance of cross road from a nearest median opening and number of U-turns along the selected section of SH-17. This shows that as length of required diversion increases, the number of U-turners stabilizes. This supports the concept that longer diversions are creating other manoeuvres by road users such as crossing the median and wrong way running. Reason for informal median openings along the highway seems to include petrol stations and other motor related trade as found from literature which needs to be considered in any strategy.

The conclusions drawn from this study apply to the corridor considered for study and may not apply for other section of road. The information made available in this study should contribute to the development of a strategy for closing medians to arrive at the best compromise between safety and mobility. The key elements and background support for the engineers decision for median closure and design of median openings found from the overall observations of the study are as follows:

1. Cars are involved in pedestrian crashes. But, also large number of car occupants are injured which could be associated with the high speed environment along the highway. This means that hopefully improved median design will result in reduced high speed crashes.

2. The dominating class of turning vehicles is motorized two wheelers and that suggests mainly short trips. This can have an impact on the design of openings, thus there is a need for turn counts during the design of openings along the corridor particularly where it may not be possible to make provision for all type of vehicles.

3. As diversion become longer due to median closures, the number of detoured vehicle stabilizes. This could well be due to illegal manoeuvres such as wrong way running. Therefore suggests that this is due to illegal manoeuvres.

4. Many Informal median openings shown to be related to motor related trade and other outlets. This will need to be considered in the development of any median closure strategy.

\section{REFERENCES}

[1] IRC:73: 2000, "Guidelines for Control of Access on Highways", Indian Road Congress, 2000.

[2] IRC:SP:84-2009 "Manual for Specifications \& Standards for Four Laning of Highways Through Public Private Partnership", Indian Road Congress, 2009.

[3] AASHTO, "A Policy on Geometric Design of Highways and Streets," 2004.
[4] Cribbins, P.D., J.W. Horn, F. V. Beeson, and R. D. Taylor, "Median Openings on Divided Highways: Their Effect on Accident Rates and Level of Service", Highway Research Record 188, Highway Research Board, 1967.

[5] Transportation Engineering, Inc., "Collision Analysis for District Wide Median Evaluation and Public Involvement," Florida Department of Transportation, 1995.

[6] Stover, V.G. Medians, A Discussion Paper, Florida Department of Transportation, December 1994.

[7] James A. Bonneson and Patrick T. Mc Coy, "Capacity and Operational Effects of Midblock Left - Turn Lanes", NCHRP Report 395, National Cooperative Highway Research Program, Transportation Research Board, 1997.

[8] ITE Committee 6Y-19, Planning Urban Arterial and Freeway Systems, Institute of Transportation Engineers, Washington, D.C., 1988). 